\title{
THE HEALTH-PROMOTING BEHAVIORS FOR MARRIED COUPLES
}

\author{
Elçin Sakmar-Balkan ${ }^{1}$, \& Hakan Kuru ${ }^{2}$ \\ ${ }^{I}$ Department of Psychology, Nuh Naci Yazgan University, Kayseri (Turkey) \\ ${ }^{2}$ Department of Physical Education and Sports, Middle East Technical University, Ankara (Turkey)
}

\begin{abstract}
The central aim of the current research is to understand the association between adult attachment style (i.e., attachment avoidance and attachment anxiety) and health-promoting behaviors of married couples in the Turkish sample. The data was gathered using demographic information form (including height and weight), Experiences in Close Relationships-Revised, and Healthy Life Style Behavior Scale II from 269 married couples. The actor-partner interdependence model (APIM) was performed to realize both intrapersonal and interpersonal effects simultaneously. Attachment avoidance and attachment anxiety were used as independent variables, health-promoting behaviors and body mass index (BMI) were used as dependent variables, and the duration of the marriage, the number of children, and the education levels of individuals were used as control variables. The saturated model demonstrated that some associations among variables were insignificant. Therefore, these insignificant relationships were reduced from the model one by one. Eventually, the final model fit the data very well $[\chi 2(13, N=269)=9.131, p=.763$, GFI $=.994, \mathrm{AGFI}=.966, \mathrm{CFI}=1, \mathrm{RMSEA}=.00]$. Dyadic analyses demonstrated that the attachment anxiety of wives was not associated with any dependent variables. The results also showed that the attachment avoidance of both husbands and wives were significantly related to their own health-promoting behaviors. In other words, both husbands and wives who had higher levels of attachment avoidant were less likely to occupy in health-promoting behaviors. Moreover, the attachment anxiety of husbands was related to the BMI of wives. In the literature, it was indicated that individuals who have attachment avoidance reported unwilling to search for medical help about their complaints because of having problems in trusting health care professionals, the worse perception of general health, and fewer exercise behaviors. Additionally, the association between husbands' high attachment anxiety and their wives low BMI may be related to the critical and often coercive style of spouses who have attachment anxiety may influence their wives' weight perception and control.
\end{abstract}

Keywords: Adult attachment, health-promoting behaviors, BMI, married couples.

\section{Introduction}

Couples start to influence each other in different perspectives during the marriage. It is known that relational factors that influence overall health (Kiecolt-Glaser \& Newton, 2001). Besides, a few reports recommend that the changes in lifestyles alters couples lifestyle behaviors and cause a direct and indirect impact on each other's wellness such as weight gain, increase or decrease in physical activity levels (Craig \& Truswell, 1988; Kahn \& Williamson, 1990). Although the effect of health-promoting behaviors on individuals' health is noticeable, the influence of marital factors needs more attention.

Many lifestyle behaviors are becoming symphonious across couples (Meyler, Stimpson, \& Peek, 2007), including nutrition (Macario \& Sorensen, 1998) and smoking (Graham \& Braun, 1999). This is partly due to assortative mating; in other words, couples with similar characteristics are more likely to marry and may also reflect the influence spouses have on each other's health behaviors (Wilson, 2002). Couple concordance may explain risk factors for the disease at the household level (Wilson, 2002). For example, spouses of patients are at increased risk of conditions including hypertension and diabetes (Hippisley-Cox \& Pringle, 1998). Also, health behavior change tends to be accordant. For instance, in a study about couples participating a family health check-up, smoking behavior, blood pressure, blood glucose, and cholesterol level were correlated across couples one year after a cardiovascular lifestyle intervention program (Pyke, Wood, Kinmonth, \& Thompson, 1997). Further, when one partner adopts a healthier behavior, the other is more likely to make a positive health behavior change (Jackson, Steptoe, \& Wardle, 2015). 
For the reason that the features of individuals have a crucial role in health-promoting behavior, several psychological variables were researched. The adult attachment styles of individuals are one of the central psychological variable associated with health-promoting behaviors. The adult attachment styles generally are classified as secure and insecure attachment; and insecure attachment includes attachment avoidance and attachment anxiety (Mikulincer \& Shaver, 2007). Resignation from closeness and dependency is mentioned as attachment avoidance, while the feelings of rejection and desertion and the attempts at excessive intimacy is stated as attachment anxiety (Harma \& Sümer, 2016). Secure attachment is revealed with low attachment avoidance and low attachment anxiety (Pietromonaco, Uchino, $\&$ Schetter, 2013). It was indicated that securely attached individuals occupy in health-promoting behaviors and talk about their symptoms (Huntsinger \& Luecken, 2004; Scharfe \& Eldredge, 2001). On the other hand, insecurely attached individuals, who have attachment avoidance or attachment anxiety, show more risky behaviors and lower health-promoting behaviors (Huntsinger \& Luecken, 2004; Savada, Busseri, Molnar, Perrier, \& DeCourville, 2009; Scharfe \& Eldredge, 2001). In other words, individuals who show insecure attachment style (i.e., anxious and avoidant attachment) tend to show riskier and fewer healthy behaviors rather than individuals who show secure attachment style.

Since marriage supplies the critical resource of attachment for many individuals (Sandberg, Busby, Johnson, \& Yoshida, 2012), it may significantly impact health behaviors (Sandberg et al., 2013). However, the majority of the research related to attachment and health-promoting behaviors examining the individual level of the relationship, not dyadic level. Moreover, the most of the studies were associated with the investigation of marriage and health indicators, such as cardiovascular risk, heart rate, and stress responses (Kiecolt-Glaser \& Newton, 2001), not health-promoting behaviors. Therefore, the main aim of the current study was to understand the association between adult attachment style (i.e., attachment avoidance and attachment anxiety) and health-promoting behaviors of married couples. Generally, it was hypothesized that attachment style of husbands and wives would predict health-promoting behaviors of couples. Specifically, the first hypothesis of the study was a spouse's attachment style would predict his or her health-promoting behaviors. The second hypothesis of the study was a spouse's attachment style would predict his or her partner's health-promoting behaviors.

\section{Method}

\subsection{Participants}

The current research included 269 heterosexual Turkish married couples (269 husbands and 269 wives). All couples had only been married once at the time of the study and had been living in big cities such as İstanbul, Ankara, and Kayseri. The length of marriages of couples ranged from 1 to 56 years with the average of 19.39 years $(S D=11.89)$. When the number of children was considered, $16.4 \%$ of couples had no child, $12.3 \%$ of couples had one child, $34.2 \%$ of couples had two children, and $37.2 \%$ of couples had three or more children. With respect to education level, $20.4 \%$ of husbands and $29.8 \%$ of wives had primary-secondary school education, $24.5 \%$ of husbands and $29.4 \%$ of wives had high school education, $47.2 \%$ of husbands and $35.3 \%$ of wives had applied schools or university degree, and $7.8 \%$ of husbands and $5.6 \%$ of wives had graduate/doctorate degree. The age of husbands ranged between 23 and 85 with the mean of $45.05(s d=11.57)$, and the age of wives ranged between 19 and 75 with the mean of 41.41 $(s d=10.80)$.

\subsection{Instruments} scales;

The instruments of the study consisted of the demographic information form and following two

Healthy Lifestyle Behavior Scale-II (HLBS-II): The HLBS-II estimates six-way of life practices under six subscales. It is a 52-item survey examines health responsibility, physical activity, nutritional habits, stress management, mental development, and interpersonal relations (Walker \& Hill-Polerecky, 1996). The Turkish version of HLBS-II has the reliability coefficients as .77 for health responsibility, .79 for physical activity, .68 for nutrition, .79 for mental development, .80 for interpersonal relationships and .64 for stress management (Bahar, Beşer, Gördes, Ersin, \& Kıssal, 2008).

Experiences in Close Relationships-Revised (ECR-R): ECR-R assesses the adult attachment styles as avoidance and anxiety (Fraley, Waller, \& Brennan, 2000). The scale contains 36 items, in which 18 items measure the attachment anxiety, whereas the other 18 items measure the attachment avoidance. The Turkish version of ECR-R has the reliability coefficients as .90 for attachment avoidance and .86 for the attachment anxiety (Selçuk, Günaydın, Sümer, \& Uysal, 2005). Regard as test-retest reliability, .82 for the attachment anxiety and .81 for the attachment avoidance were shown. 


\subsection{Data analysis}

Obtained data were analyzed using several techniques. Descriptive statistics and bivariate analysis were conducted by using the IBM SPSS 20 program. The model among adult attachment style, health-promoting behaviors, and BMI was formed by controlling the length of the marriage, the number of children, and education levels of spouses. In order to test the model, APIM (Ledermann, Macho, \& Kenny, 2011), which is to comprehend both intrapersonal and interpersonal effects simultaneously, were conducted by using IBM AMOS.

\section{Results}

\subsection{Descriptive statistics and bivariate analysis}

Regarding the main variables of the current research, the mean scores were calculated for wives and husbands separately. The mean score of the attachment avoidance for husbands was $2.03(s d=0.81)$ and for wives was $2.13(s d=0.97)$. The mean score of the attachment anxiety for husbands was 2.77 $(s d=0.86)$ and for wives was $2.89(s d=0.92)$. The mean score of the health-promoting behaviors $(\mathrm{HPB})$ for husbands was $131.53(s d=20.27)$ and for wives was $133.78(s d=17.37)$. The mean score of the BMI for husbands was $27.07(s d=3.28)$ and for wives was $25.91(s d=4.30)$.

Both intrapersonal and interpersonal correlations were calculated for the main variables and are shown in Table 1.

Table 1. Bivariate correlations of main variables of the study.

\begin{tabular}{lllllllll}
\hline & $\mathbf{1}$ & $\mathbf{2}$ & $\mathbf{3}$ & $\mathbf{4}$ & $\mathbf{5}$ & $\mathbf{6}$ & $\mathbf{7}$ & $\mathbf{8}$ \\
\hline 1. Wives' avoidance & 1 & & & & & & & \\
2. Husbands' avoidance & $.51^{* *}$ & 1 & & & & & & \\
3. Wives' anxiety & $.45^{* *}$ & $.40^{* *}$ & 1 & & & & & \\
4. Husbands' anxiety & $.28^{* *}$ & $.56^{* *}$ & $.45^{* *}$ & 1 & & & & \\
5. Wives' HPB & $-.29^{* *}$ & $-.20^{* *}$ & $-.13^{*}$ & $-.13^{*}$ & 1 & & & \\
6. Husbands' HPB & $-.19^{* *}$ & $-.26^{* *}$ & $-.16^{* *}$ & $-.21^{* *}$ & $.30^{* *}$ & 1 & & \\
7. Wives' BMI & $.14^{*}$ & .02 & -.04 & -.08 & -.08 & -.02 & 1 \\
8. Husbands' BMI & .03 & .05 & -.08 & .01 & -.01 & .01 & $.31^{* *}$ & 1 \\
\hline
\end{tabular}

Note. ${ }^{*} p<.05 ; * * p<.001$

\subsection{Testing the model}

The conceptual model was committed to as the attachment avoidance and anxiety would have direct effects on health-promoting behaviors and BMI by controlling the length of the marriage, the number of children, and the education levels of spouses. Hereby, the model was saturated indicating observed and implied covariance matrices fitted exactly. The saturated model comprised insignificant links, so they were dropped from the model. Eventually, the final model fit the data very well $[\chi 2(13, N=269)=9.131, p=.763, \mathrm{GFI}=.994, \mathrm{AGFI}=.966, \mathrm{CFI}=1, \mathrm{RMSEA}=.00]$

Figure 1. Actor and partner effects in predicting health-promoting behaviors and BMI.

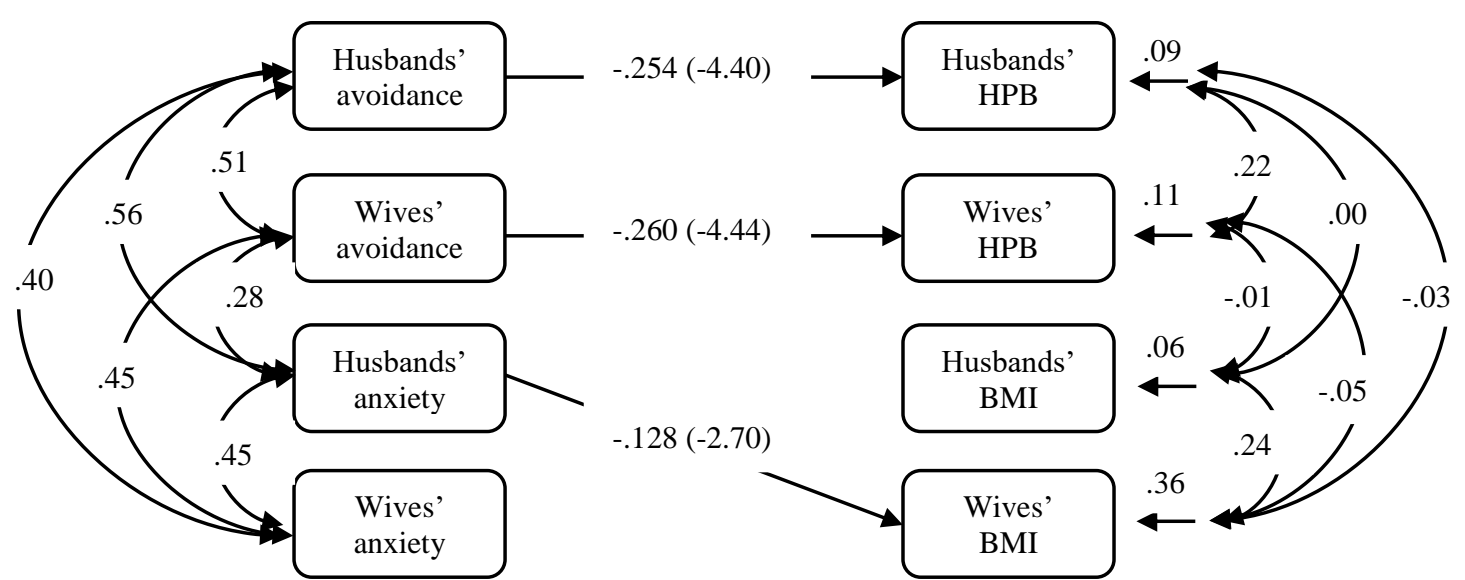

Note. Error terms represent the percent of the unexplained variance. For ease of interpretation, control variables, and correlation among IVs and control variables are not shown. $t$ values are presented in the parentheses next to standardized regression weights. 
The APIM analysis disclosed significant relationships for both actor and partner effects. Specifically, both husbands and wives high in the attachment avoidance reported low health-promoting behaviors $(\beta=-0.254, p<.001 ; \beta=-0.260, p<.001$, respectively). In other words, both husbands and wives who had higher levels of attachment avoidant were less likely to occupy in health-promoting behaviors. Moreover, husbands high in the attachment anxiety lead to low BMI of their wives $(\beta=-0.128$, $p<.007)$, indicating that husbands reported high attachment anxiety predicted low wives' BMI. Overall, adult attachment style explained $11.3 \%, 9.2 \%$, and $36.5 \%$ of the total variances in wives' and husbands' health-promoting behaviors and wives' BMI, respectively. Results showed that the paths for husbands and wives were comparable and there was no gender difference in the association between own attachment avoidance and own health-promoting behaviors.

\section{Discussion}

The study aimed to identify the relationship between adult attachment style and health-promoting behaviors. As expected, the current research found that both husbands and wives who showed higher attachment avoidance tended to behave less health-promoting. In the literature, it was indicated that attachment avoidance of individuals reported lower health-promoting behaviors such as unwilling to search for medical help, having problems in trusting health care professionals (Feeney \& Ryan, 1994), the worse perception of general health, and the physical inactivity (Kafescioglu, Thomas, \& Shields, 2010). On the other hand, attachment anxiety of individuals was not related to their health-promoting behaviors in the current study. Feeney (1995) reported that attachment anxiety is negatively associated with reporting the level of exercise and positively associated with reporting need to lose weight. Therefore, to examine health-promoting behaviors specifically may be more helpful to understand the relation.

Inconsistent with our expectations, the paths from adult attachment style to health-promoting behaviors are much more of an intrapersonal than an interpersonal phenomenon. In other words, both attachment avoidance and anxiety of individuals was not associated with their partners' health-promoting behaviors; partner effects were not shown for health-promoting behaviors. Individuals who have high attachment avoidance do not feel comfortable with providing and receiving care and support in their relationships (Kafescioglu, et al., 2010). They may see this kind of behaviors as restraining their independence. So, they may avoid affecting their spouse's health-promoting behaviors. Further, direct or indirect attempts of any behavioral change to spouse have a risk to be understood as the dissatisfaction of the relationship and/or to cause the dissatisfaction of their spouses. Hence, because of the fear of abandonment and rejection in a relationship is one of the main characteristics of individuals with high attachment anxiety (Mikulincer \& Shaver, 2007) who are sensitive to cues of possible rejection (see, Campbell, Simpson, Boldry, \& Kashy, 2005), they may abstain from any conscious or unconscious interfere to their spouse's health-promoting behaviors.

Considering the BMI of individuals, the findings, which showed no relationship between own attachment style and BMI, are consistent with the literature such as Koskina and Giovazolias' study (2010). The attachment anxiety of husbands, but not wives, was related to the BMI of their spouses in the current research. Being married has a more significant influence on men's health than relationship quality (Umberson, 1992). So, the characteristics of wives may be not so important for husbands' BMI. On the other hand, husbands reported high attachment anxiety lead to low wives' BMI in the current study. It is known that women may be sensitive to social pressure towards thinness. Individuals whose spouses have higher attachment anxiety reported their interactions as dissatisfying, negative in tone, low in amount, and low in the intimacy of disclosure (Bradford, Feeney, \& Campbell, 2002). The critical and often coercive style of these spouses may influence their wives' weight perception and control.

\section{References}

Bahar, Z., Beşer, A., Gördes, N., Ersin, F., \& Kıssal, A. (2008). Sağlıklı yaşam biçimi davranışları ölçeği II'nin geçerlik ve güvenirlik çalısması [Healthy life style behavior scale II: A reliability and validity study]. Cumhuriyet Üniversitesi Hemşirelik Yüksekokulu Dergisi, 12(1), 1-13.

Bradford, S. A., Feeney, J. A., \& Campbell, L. (2002). Links between attachment orientations and dispositional and diary-based measures of disclosure in dating couples: A study of actor and partner effects. Personal Relationships, 9, 491-506.

Campbell, L., Simpson, J. A., Boldry, J. G., \& Kashy, D. A. (2005). Perceptions of conflict and support in romantic relationships: The role of attachment anxiety. Journal of Personality and Social Psychology, 88, 510-531. 
Craig, P. L., \& Truswell, A. S. (1988). Dynamics of food habits of newly married couples: food-related activities and attitudes towards food. Journal of Human Nutrition and Dietetics, 1(6), 409-419.

Feeney, J. A. (1995). Adult attachment, coping style and health locus of control as predictors of health behavior. Australian Journal of Psychology, 47(3), 171-177.

Feeney, J. A., \& Ryan, S. M. (1994). Attachment style and affect regulation: Relationship with health behavior and family experiences of illness in a student sample. Health Psychology, 13(4), 334-345.

Fraley, R. C., Waller, N. G., \& Brennan, K. A. (2000). An item-response theory analysis of self-report measures of adult attachment. Journal of Personality and Social Psychology, 78, 350-365.

Graham, K., \& Braun, K. (1999). Concordance of use of alcohol and other substances among older adult couples. Addictive Behaviors, 24(6), 839-856.

Harma, M., \& Sümer, N. (2016) Are avoidant wives and anxious husbands unhappy in a collectivist context? Dyadic associations in established marriages. Journal of Family Studies, 22, 63-79.

Hippisley-Cox, J., \& Pringle, M. (1998). Are spouses of patients with hypertension at increased risk of having hypertension? A population-based case-control study. British Journal of General Practice, 48(434), 1580-1583.

Huntsinger, E. T., \& Luecken, L. J. (2004). Attachment relationships and health behavior: The mediational role of self-esteem. Psychology and Health, 19(4), 515-526.

Jackson, S. E., Steptoe, A., \& Wardle, J. (2015). The influence of partner's behavior on health behavior change: the English Longitudinal Study of Ageing. JAMA Internal Medicine, 175(3), 385-392.

Kafescioglu, N., Thomas, V., \& Shields, C. G. (2010). Dyadic and mediation analyses of coping with cardiovascular disease. Procedia Social and Behavioral Sciences, 5, 216-220.

Kahn, H. S., \& Williamson, D. F. (1990). The contributions of income, education and changing marital status to weight change among US men. International Journal of Obesity, 14(12), 1057-1068.

Kiecolt-Glaser, J. K., \& Newton, T. L. (2001). Marriage and health: His and hers. Psychological Bulletin, 127(4), 472-503.

Koskina, N., \& Giovazolias, T. (2010). The effect of attachment insecurity in the development of eating disturbances across gender: The role of body dissatisfaction. The Journal of Psychology, 144(5), 449-471.

Ledermann, T., Macho, S., \& Kenny, D. A. (2011). Assessing mediation in dyadic data using the actor-partner interdependence model. Structural Equation Modeling, 18, 595-612.

Macario, E., \& Sorensen, G. (1998). Spousal similarities in fruit and vegetable consumption. American Journal of Health Promotion, 12(6), 369-377.

Meyler, D., Stimpson, J. P., \& Peek, M. K. (2007). Health concordance within couples: a systematic review. Social Science \& Medicine, 64(11), 2297-2310.

Mikulincer, M., \& Shaver, P. R. (2007). Attachment in adulthood: Structure, dynamics, and change. New York: Guilford.

Pyke, S. D., Wood, D. A., Ann-Louise, K., \& Thompson, S. G. (1997). Change in coronary risk and coronary risk factor levels in couples following lifestyle intervention: the British Family Heart Study. Archives of Family Medicine, 6(4), 354.

Pietromonaco, P. R., Uchino, B., \& Schetter, C. D. (2013). Close relationship processes and health: Implications of attachment theory for health and disease. Health Psychology, 32(5), 499-513.

Sandberg, J. G., Busby, D. M., Johnson, S. M., \& Yoshida, K. (2012). The brief accessibility, responsiveness, and engagement (BARE) scale: A tool for measuring attachment behavior in couple relationships. Family Process, 51(4), 512-526.

Sandberg, J. G., Harper, J. M., Hill, E. J., Miller, R. B., Yorgason, J. B., \& Day, R. D. (2013) "What happnes at home does not necessarily stay at home": The relationship of observed negative couple interaction with physical health, mental health, and work satisfaction. Journal of Marriage and Family, 75(4), 808-821.

Savada, S. W., Busseri, M. A., Molnar, D. S., Perrier, C. P. K., \& DeCourville, N. (2009). Investigating a four-pathway model of adult attachment orientation and health. Journal of Social and Personal Relationships, 26(5), 604-633.

Scharfe, E., \& Eldredge, D. (2001). Associations between attachment representations and health behaviors in late adolescence. Journal of Health Psychology, 6(3), 295-307.

Selçuk, E., Günaydın, G., Sümer, N., \& Uysal, A. (2005). A new measure for adult attachment styles: The psychometric evaluation of experiences in close relationships-revised (ECR-R) on a Turkish sample. Turkish Psychological Articles, 8, 1-11.

Umberson, D. (1992). Gender, marital status, and the social control of health behavior. Social Science \& Medicine, 34, 907-917.

Walker, S. N., Hill-Polerecky, D. M. (1996). Psychometric evaluation of the Health Promoting Lifestyle Profile II. Unpublished manuscript, University of Nebraska Medical Center.

Wilson, S. E. (2002). The health capital of families: an investigation of the inter-spousal correlation in health status. Social Science \& Medicine, 55(7), 1157-1172. 